\title{
Recent advances in understanding osteosarcoma and emerging therapies
}

\author{
Nathalie Gaspar ${ }^{1,2^{*}} \quad$ Maria Eugenia Marques da Costa ${ }^{2}$ Olivia Fromigue ${ }^{3,4}$ Robin Droit ${ }^{2}$ Pablo Berlanga ${ }^{1}$ \\ Antonin Marchais ${ }^{2}$ \\ ${ }^{1}$ Department of Oncology for Child and adolescent, Gustave Roussy cancer campus. France \\ ${ }^{2}$ National Institute for Health and Medical Research (INSERM) U1015, Gustave Roussy, France \\ ${ }^{3}$ INSERM, UMR981, France \\ ${ }^{4}$ Université Paris Sud, Orsay, France
}

\begin{abstract}
Osteosarcoma is the most common bone cancer in adolescents and young adults, but it is a rare cancer with no improvement in patient survival in the last four decades. The main problem of this bone tumor is its evolution toward lung metastatic disease, despite the current treatment strategy (chemotherapy and surgery). To further improve survival, there is a strong need for new therapies that control osteosarcoma cells with metastatic potential and their favoring tumor microenvironment (ME) from the diagnosis. However, the complexity and heterogeneity of those tumor cell genomic/epigenetic and biology, the diversity of tumor ME where it develops, the sparsity of appropriate preclinical models, and the heterogeneity of therapeutic trials have rendered the task difficult. No tumor- or ME-targeted drugs are routinely available in front-line treatment. This article presents up-to-date information from preclinical and clinical studies that were recently published or presented in recent meetings which we hope might help change the osteosarcoma treatment landscape and patient survival in the near future.
\end{abstract}

\section{Keywords}

Osteosarcoma, Therapy, Precision medicine, Omics

\section{Peer Review}

The peer reviewers who approve this article are:

1. Zhenfeng Duan, Sarcoma Biology Laboratory, Department of Orthopaedic Surgery, David Geffen School of Medicine at UCLA, Los Angeles, CA, USA

Competing interests: No competing interests were disclosed.

2. Katherine A. Janeway, Pediatrics, Dana-Farber/Boston Children's Cancer and Blood Disorders Center, Boston, Massachusetts, USA

Competing interests: No competing interests were disclosed. 
*Corresponding author: Nathalie Gaspar (nathalie.gaspar@gustaveroussy.fr)

Competing interests: NG is the principal investigator of the first-line trial Sarcoma 13 and the second-line trial. OLIE. MEMC, OF, RD, PB, and AM declare that they have no competing interests.

Grant information: The "osteomic" research programme (U1015) is funded by the association Etoile de Matin, une Main Vers l'Espoir, la Ligue nationale contre le cancer, the French Society of Pediatric Oncology (SFCE, société Française des cancers et leucémie de l'Enfant et l'adolescent), and the Bristol-Myers Squibb Foundation. The OS2006 clinico-biological database was funded by SFCE and the association Imagine for Margo. The French Biological OSTeosarcoma Data Sharing program (BoOST-dataS) is funded by the French National Institute of Cancer (INCa) and approved by the intergroup InterSARC.

The funders had no role in study design, data collection and analysis, decision to publish, or preparation of the manuscript.

Copyright: $\odot 2020$ Gaspar N et al. This is an open access article distributed under the terms of the Creative Commons Attribution License, which permits unrestricted use, distribution, and reproduction in any medium, provided the original work is properly cited.

How to cite this article: Gaspar N, Marques da Costa ME, Fromigue O, Droit R, Berlanga P and Marchais A. Recent advances in understanding osteosarcoma and emerging therapies. Faculty Reviews 2020 9:(18) https://doi.org/10.12703/r/9-18

Published: 26 Nov 2020, Faculty Reviews 9:(18) https://doi.org/10.12703/r/9-18 


\section{Introduction}

Osteosarcoma is the most common bone cancer in adolescents and young adults $(80 \%$ of the patients are younger than 25 years old) but is a rare cancer (estimated incidence of 0.2 to 3 new cases/million per year in Europe $)^{1}$. Survival of these patients has not improved in the last four decades. The main problem of this bone tumor is its evolution toward lung metastatic disease. Patient survival decreases when lung metastasis are present at diagnosis regardless of the chemotherapy regimen used ${ }^{2-5}$ or when lung metastasis appeared during the disease evolution (3-year progression-free survival [PFS] is around $20 \%)^{6-8}$.

Primary tumor surgery is an important part of the treatment, as unresectable osteosarcoma has poorer survival. Osteosarcoma chemosensitivity was demonstrated in the 1970s to $1980 \mathrm{~s}$ with response rates of 19 to $40 \%$ to methotrexate, cis-platinum, adriamycin, ifosfamide, and etoposide 9 . Since then, first-line standard treatment has not been modified and includes neoadjuvant and post-operative multi-drug chemotherapy associated with surgical resection of the primary tumor and all remaining metastatic localizations if present ${ }^{10}$. In addition to the presence of initial metastases, histological response of the primary tumor to neoadjuvant chemotherapy is a strong prognostic factor of relapse $^{4}$. Intensification of chemotherapy at diagnosis or relapse has not modified patient outcome ${ }^{3,11}$. Extensive efforts to identify more effective or less toxic regimens, both at diagnosis and relapse, have been disappointing up to now 6 .

This emphasizes the strong unmet need for new therapies to improve survival for these patients ${ }^{6}$. The main objective would be to control osteosarcoma cells with metastatic potential and their favoring tumor microenvironment (ME) from the diagnosis. However, the complexity and heterogeneity of those tumor cell genomic/epigenetic and biology ${ }^{12}$ as well as the diversity of tumor ME where it develops (bone primary tumor and lung metastatic niche) have rendered the task difficult. No phase II trial in relapse osteosarcoma has yet been transposed to consensual successful first-line phase III trials ${ }^{6}$. No tumor- or ME-targeted drugs are routinely available in front-line treatment. This article presents up-to-date information that was published or presented in recent meetings and that we hope might help change the osteosarcoma treatment landscape and survival in the near future.

\section{The complexity of osteosarcoma biology: what are next-generation sequencing tools bringing? What remains to be solved?}

In recent years, the scientific community has started to unscramble osteosarcoma complex genomic ${ }^{13,14}$ with next-generation sequencing (NGS), mainly at the DNA level (whole exome sequencing [WES] and whole genome sequencing [WGS]). They first characterized the considerable levels of phenotypic heterogeneity, aneuploidy, and the high rate of complex chromosomic aberrations (copy number alterations, kataegis, and chromothripsis) across the whole genome $\mathrm{e}^{12,13,15,16}$ in osteosarcoma. Gene-centric studies have all converged to describe TP53 deficiency as the major early oncogenic event probably underestimated until the discovery of intronic TP53 mutations ${ }^{17}$. Few other recurrent mutations have been observed in DNA repair and cell cycle genes at the somatic (for example, RB1, ATRX, and PTEN/PI3K) ${ }^{15}$ and constitutional (osteosarcoma predisposing syndromes include alterations of TP53, RB1, and RECQL4) ${ }^{18}$ level. DNA repair and cell cycle pathways are also recurrently altered at a genomic level (for example, recurrent deletions TP53, RB1, CDKN2A/B genes, or recurrent amplifications, COPS3, CCNE1, MDM2/CDK4, MYC genes, and 6p12.3 amplifications) in addition to several receptor tyrosine kinases and downstream pathways (for example, recurrent amplifications in WNT, insulin-like growth factor 1 receptor [IGF1R], PI3K, and MAPK pathways) ${ }^{14-16}$. Besides genetic alterations, accumulating evidence highlights the important role of epigenetic modulation in osteosarcoma oncogenesis ${ }^{12,14,19}$, although this role is not fully understood.

In parallel to the emergence of new questions, the advances in osteosarcoma molecular description, achieved with NGS technology, also participated to the complexity of the general picture such as some previous unsolved problems might seem even more obfuscated now. We still have to identify the initial osteosarcoma oncogenic events with, as a subsidiary enigma, the exceptional resilience of osteosarcoma cell population to survive and expand while having such a chaotic genome. Complexity which also estranged the definition, trivial in other pathologies, of key oncogenic drivers paving disease emergence or progression to metastasis, delaying the implementation of routinely usable prognostic biomarkers or robust molecular/biological stratification able to drive future therapeutic development.

Other investigations such as transcriptomic analysis-RNA expression level and RNA sequencing (RNA-seq) - could be a better/upper read-out of what is occurring in tumor cells, tumor $\mathrm{ME}$, and their interplay ${ }^{20}$. Indeed, the osteosarcoma transcriptomic landscape and its diversity might better sum up, as the first phenotype, the multiple chromosomal rearrangements, the epigenetic events ${ }^{13,15}$, but also the various tumor ME (bone primary tumor, circulating cells, and lung metastatic site) and their heterogeneity (for example, osteoforming and osteolytic areas in bone primary but also lung metastasis ${ }^{21}$ and hypoxic area). The interplay between tumor cells and ME cells and the identity of cells that influence osteosarcoma fate remain unclear.

To fully reveal the global osteosarcoma molecular picture, including its ME, large-scale approaches should couple integrative analyses at both the DNA/RNA level and upper levels (for example, the proteome level). Owing to the rarity of these patient samples, the collection of the optimal dataset requires an effort to merge existing genomic/biological datasets with optimal clinical annotation to ease researchers' work in the field. Very few osteosarcoma genomic datasets are available worldwide, usually with no detailed and sparse clinical annotation, and issued from samples mainly at diagnosis (for example, the TARGET dataset and others ${ }^{20,22,23}$ ). Relapse samples, which might give access to clonal evolution and metastatic phenotype, are even rarer, but the situation is improving. Several molecular profiling 
programs have been set up at relapse $\mathrm{e}^{24,25}$, and data should be available soon for the research community.

Multi-regional WES/WGS in primary and metastatic matched samples from patients with osteosarcoma has started to reveal the dynamic evolutionary process and temporo-spatial tumor heterogeneity of osteosarcoma lung metastases ${ }^{26}$. Thus, metastases exhibit a higher mutational burden, genomic instability, improved immunogenicity, and a more significant inter-tumoral rather than intra-tumoral heterogeneity ${ }^{26}$. The pro-metastatic role of tumor-associated exosomes, micro-RNA, long non-coding RNA, circular RNA, and metabolism is just starting to be explored $^{27}$. The combination of identification and quantification of somatic alterations in plasma-derived ctDNA (circulating tumor DNA) is gaining traction as a non-invasive and cost-effective method of disease monitoring in patients with osteosarcoma, particularly to evaluate the response to treatment and monitor for disease recurrence ${ }^{28}$. However, prospective validations in larger cohorts are needed.

Understanding the clonal dynamics during osteosarcoma disease evolution from primary tumor to metastatic sites might be a clue for future therapeutics. Several new technologies are starting to create wider opportunities to achieve this goal. The next revolution will come from NGS moving from bulk to single-cell tumor analysis. Single-cell NGS is clearly the next step that might help us understand the osteosarcoma cell of origin, initial oncogenic event(s), and the clonal and ME dynamics along the disease progression from primary tumor, through circulating cells, toward the lung metastatic site. A near single-cell tracking system in a de novo-induced murine osteosarcoma model suggests that osteosarcomagenesis could follow a neutral evolution model, in which different cancer clones coexist and propagate simultaneously $^{29}$. In the near future, single-cell whole-genome and transcriptomic analyses offer great promise in deciphering the local and global interactions driving the tumor-host dynamic within the primary tumor and the metastatic niche ${ }^{30}$. However, the bone ME might be challenging for single-cell isolation in human disease. In addition, single-cell resolution comes at the cost of losing the spatial organization of the tumor ME. Other technologies such as spatial transcriptomic might provide excellent integration of nearly single-cell transcriptomic with histopathological analysis. Such technology will produce detailed maps of the tumor and ME cells in each tumor sample, unravelling spatial arrangement and which types of crosstalk may occur between tumor and ME cells according to the context (bone/lung localization). This should allow a deeper understanding of the important targets in osteosarcoma.

\section{Targeting the tumor cells: moving toward a personalized medicine?}

Although the decoding of the osteosarcoma genome greatly advanced the understanding of the genomic osteosarcoma landscape from early oncogenesis to metastatic spread properties, immediately actionable therapeutic targets are not yet obvious. So far, preclinical data have not translated to a successful targeted therapy phase II relapse trial ${ }^{6}$.
Up to now, only few targeted agents have been tested in a phase II trial for refractory/recurrent osteosarcomas, the setup of such trials started late compared with that of other cancer trials (>2007), and their efficacy results were disappointing ${ }^{6}$. The biological rationale leading to these phase II trials was usually light. When described, it relied mainly on the general mechanism of drugs/combination activity in cancers rather than on specific osteosarcoma targets (for example, mammalian target of rapamycin [mTOR] inhibitors) or on the relative expression level of osteosarcoma cell surface protein with little knowledge about its mechanistic role (for example, anti-GD2, anti-HER2). This clearly reflects the lack of strong preclinical studies in osteosarcoma at that time. More specific therapeutic development based on osteosarcoma biology is being attempted. For example, the BRCAness phenotype of osteosarcoma ${ }^{22}$ is being exploited as a therapeutic target for poly ADP ribose polymerase (PARP) inhibition ${ }^{31}$. In vitro results seem less impressive than what was observed in BRCA-deficient breast cancer ${ }^{32}$. Clinical relevance in patients is being evaluated in ongoing trials (for example, e-smart trial PARP inhibitor arm, NCT02813135). In addition to needing better knowledge of osteosarcoma biology, we need appropriate and available preclinical models to properly perform preclinical drug evaluation and to define the level of preclinical evidence required to study a new drug in patients. Efforts have been made in the last few years to improve preclinical testing of drugs by developing patient-derived xenograft (PDX) models from primary tumor at diagnosis or metastatic relapse, including in the bone orthotopic setting (ITCC-P4, www.itccp4.eu; NCI PPTC, www.ncipptc.org), but no minimum preclinical requirement to bring a drug to the clinic has been defined for osteosarcoma.

Targeting the initial oncogenic event or those responsible for the metastatic phenotype (or both) would be a great help in osteosarcoma. The mechanism facilitator of lung metastasis remains to be identified from tumor cells, primary bone tumor ME, or lung metastatic ME; they may represent clinically relevant targets. Preclinical proof of concept of personalized medicine targeting osteosarcoma abnormalities was shown in PDX models. Orthotopic osseous osteosarcoma PDX models issued from primary tumor at diagnosis or metastatic relapse retain the tumor characteristics of the patient sample they are issued of, with the best clonal preservation across different pediatric tumors, as well as cellular features of the patient tumor and the epigenetic landscape of their developmental origins ${ }^{33}$. Via such PDX models and an integrated approach (WGS and matched RNA-seq) to identify somatic copy number alterations with the most highly amplified genes, a limited set of copy number patterns can group osteosarcoma tumors into subtypes that may predict response to certain targeted agents (for example, genome-informed targeting of MYC/CDK9, Cyclin E/CDK2, CDK4/6, PI3K/AKT/PTEN/mTOR, AURKB, and VEGF pathways $)^{34}$. These data can be used to inform new agent prioritization decisions for drug development in osteosarcoma and open the field of cell cycle inhibitors as anti-osteosarcoma drugs along with other publications. However, these altered patterns explain only a small number of events, and the degree of cell-to-cell 
heterogeneity within a tumor remains unknown. Furthermore, translation to humans remains to be proven. Several molecular-driven therapeutic programs are ongoing (for example, e-SMART, NCT02813135; INFORM2, NCT03838042; and the MATCH Screening Trial, NCT03155620), including with drugs of potential interest in osteosarcoma (e-SMART, NCT02813135, CDK4/6 inhibitor arms), and results are eagerly awaited. These programs are based mostly on WES abnormalities while gene expression by RNA-seq is usually not taken into account. This might be thought out differently in the future.

\section{Targeting the microenvironment: hope or despair? Moving toward a combined or an adapted ME strategy?}

The genomic complexity and tumor heterogeneity of osteosarcoma as well as the importance of ME (osseous, angiogenic, and immune ME) in osteosarcoma metastatic phenotype and outcome have orientated drug development toward ME-directed drugs at a different level for the last two decades. Some efficacy of these strategies has been observed in phase II trials at relapse. Fewer attempts to introduce such drugs then in first-line treatment have not yet been successful, but some are still ongoing. Again, the reliability of the preclinical models that do not recapitulate the whole human ME is questionable. Humanized models or syngenic models, including spontaneous osteosarcoma in dogs, are being explored.

\section{Osteosarcoma immune microenvironment}

Osteosarcoma is a macrophage-dependent tumor with few lymphocytes present in its hostile hypoxic tumor ME. Tumor immunity plays an important role in osteosarcoma metastatic behavior. Localized tumors at diagnosis present high tumor-infiltrating macrophages (TAMs) of M1 polarisation associated with a low rate of tumor-infiltrating lymphocytes (TILs) and a balance in favor of CD8 effectors ${ }^{35,36}$. In contrast, primary tumors issued from metastatic patients present M2-polarised TAMs with immunosuppressive, tissue remodeling, and pro-angiogenic properties $^{37}$ and also exhausted/anergic $\mathrm{CD}^{+}$ TILs $^{38}$ and a balance favoring the immunosuppressive FOXP3 ${ }^{+}$ $\mathrm{T}$ regulator $(\text { Treg })^{36}$. This pro-tumor immune contexture appears to be enhanced in lung metastasis samples ${ }^{35,39}$. Rather than a clear dichotomic situation, a continuum between both states due to ME heterogeneity might better mimic the reality of osteosarcoma immune ME, explaining some apparent conflicting results ${ }^{40}$. The relative role of the tumor immune profile or the patient immune profile is not yet understood. Owing to this osteosarcoma immune ME, immune therapy has been considered an excellent choice for targeting osteosarcoma metastatic phenotype.

Therefore, targeting the intra-tumor macrophage environment by liposomal mifamurtide (L-MTP-PE, MEPACT ${ }^{\circledR}$ ) as an immune modulator able to activate monocytes/macrophages was promising in phase $\mathrm{II}^{41}$. The controversial results on mifamurtide efficacy associated with post-operative chemotherapy, issued from the Intergroup INT-0133 phase III study, in localized osteosarcoma $^{42,43}$ and the insufficient power of the analysis performed separately in metastatic patients ${ }^{44}$, have not led to a homogenized international use of this drug. The US Food and Drug Administration did not approve the drug, whereas the European Medicines Agency approved the drug for localized osteosarcoma, but mifamurtide is still not reimbursed in all European countries. The current first-line French sarcoma 13/OS2016 (NCT03643133) randomized phase II trial in high-risk osteosarcoma (distant/skip metastatic disease at diagnosis and localized disease with poor histological response) might help to resolve this question ${ }^{45}$. Interferon alfa failed to show efficacy and was considered toxic in a first-line phase III EURAMOS trial ${ }^{2}$. Lymphocyte-targeted immune therapies with check-point inhibitors (anti-PD1/PDL1) were disappointing in refractory/relapsed osteosarcoma phase I/II trials with the majority of the patients experiencing progressive disease when anti-PD1/PDL1 was given either as single agent ${ }^{46,47}$ or combined with metronomic cyclophosphamide ${ }^{48}$. However, recent data comparing the metastatic and primary tumor niches ${ }^{30}$ suggested that relapse disease might not be the best population to test such drugs, and anti-PDL1 is now being tested as maintenance after adjuvant first-line chemotherapy (NCT03676985).

\section{Osteosarcoma vascular microenvironment}

Angiogenic pathways-for example, vascular endothelial growth factor receptor (VEGFR) and platelet-derived growth factor (PDGF) - have been implicated in osteosarcoma tumor evolution and linked with their metastatic behavior and poor prognosis. Targeting the tumor vascular environment with multi-tyrosine kinase inhibitor harboring anti-angiogenic activity (targeting VEGFR, PDGF receptor, and fibroblast growth factor receptor) is the most promising therapeutic option at the moment in relapsed/refractory osteosarcoma but with no known biomarker of efficacy. Whether the anti-osteosarcoma activity is due only to their angiogenic properties or to an additional role on tumor cells is still unknown. Several multi-tyrosine kinase inhibitors have been tested as a single agent in both adult/pediatric populations (regorafenib randomized phase II against placebo $^{49,50}$; single-arm phase II trials of sorafenib ${ }^{51}$, apatinib ${ }^{52}$, cabozantinib $^{53}$, and lenvatinib ${ }^{54}$ ) with a class effect efficacy (median PFS ranged between 3 and 6 months, whereas median PFS for placebo was 4 weeks). The main side effects (for example, hypothyroidy, hypertension, and proteinuria) are usually manageable by dose reduction and symptomatic measures. The relation between efficacy and observed side effects is not clear. No unanimous biomarker of efficacy exists. Pneumothorax is observed in 6 to $17 \%$ of patients with lung metastases. This seems to be a class effect, specific to osteosarcoma, as it is extremely infrequent in other tumor types (incidence $<1 \%$ ). Currently, the regorafenib single agent is being introduced in first-line treatment as maintenance treatment after the end of the conventional chemotherapy for patients in complete remission (REGOSTA, NCT04055220). Unfortunately, although data on efficacy/toxicity in children/adolescents are available, the REGOSTA trial includes only patients who are 16 years old and above. Combining this drug with others might be challenging. The combination sorafenib/mTOR inhibitor was poorly tolerated and did not exhibit increased efficacy ${ }^{55}$. The combination lenvatinib+VP16/ ifosfamide was feasible with acceptable toxicity, mainly 
chemotherapy-related $^{54}$. A randomized phase II trial VP16/ ifosfamide with or without lenvatinib in relapsed osteosarcoma has just opened (OLIE, NCT04154189).

\section{Osteosarcoma bone microenvironment}

Osteosarcomas are characterized by the direct formation of osteoid matrix by tumor cells $\mathrm{s}^{56}$, associated with osteolytic lesions. The invasion of bone tissue by tumor cells, through their ability to deregulate bone remodeling, affects the balance between bone resorption (osteoclasts) and bone formation (osteoblasts). A vicious cycle between tumor and bone cells is described during osteosarcoma development. Cancer cells produce soluble factors, such as cytokines-for example, interleukin-6 (IL-6), IL-11, tumor necrosis factor alpha (TNF- $\alpha$ ), and receptor activator of nuclear factor kappa-B ligand (RANKL) - that activate osteoclastogenesis, leading to bone degradation. Following bone resorption, growth factors trapped in the bone matrix, such as IGF-1 or transforming growth factor beta (TGF- $\beta$ ), are released in the bone ME and stimulate tumor growth ${ }^{57}$. Targeting the osteoclastic activity was thought to be an interesting target in osteosarcoma.

Despite preclinical marked evidence in mouse/rat models ${ }^{58,59}$, zoledronate, a biphosphonate with anti-osteoclastic activity, failed to show added efficacy to chemotherapy in the French first-line OS2006 phase III trial ${ }^{60}$, confirmed by a Chinese trial ${ }^{61}$. One hypothesis for the lack of efficacy in patients with osteosarcoma is a potential deleterious effect of zoledronate on the immune system ${ }^{40}$ and/or the heterogeneity of tumor ME, not properly captured in animal models ${ }^{21}$. In a phase II trial (NCT02470091) in the US, the RANKL inhibitor denosumab (Prolia ${ }^{\circledR}$ ) also had insufficient activity in refractory/recurrent osteosarcoma for further development ${ }^{62}$.

\section{Osteosarcoma lung microenvironment}

The bone ME seems to be reproduced in osteosarcoma lung metastatic foci, and differences compared with primary tumor are observed, especially in the immune ME, which seems more immunosuppressive in metastasis ${ }^{30,35}$. In addition, very little is known about the biology that drives lung colonization and the specificity of the lung niche leading to osteosarcoma proliferation or dormancy ${ }^{63}$. More should be understood to use it as a therapeutic target.

\section{How to move forward with osteosarcoma tumor microenvironment}

In the future, simultaneously targeting several aspects of the osteosarcoma ME might be more efficient than targeting only one aspect. Preclinical evidence suggests increased anti-osteosarcoma efficacy when zoledronate and L-MTP-PE are associated ${ }^{64}$. A French clinical phase II trial in sarcoma including osteosarcoma, combining both an anti-PD1 and a multi-tyrosine kinase inhibitor with angiogenic activity, should open soon. Another option would be to tailor ME modulation therapies to the ME heterogeneity of each individual tumor. This last strategy will require reliable markers of the tumor $\mathrm{ME}$ characteristics and is a field of further development.

\section{Drug development in osteosarcoma: how to improve trial design}

In this review, we have discussed several key elements to speed up drug development in osteosarcoma: a better biological understanding of tumor cells, tumor $\mathrm{ME}$, and metastatic processes; more reliable preclinical models reflecting tumor cell heterogeneity and tumor ME; and the need to identify prerequisites to bring a drug for preclinical testing to patients.

Another important question is how to optimize trial design to rapidly evaluate the efficacy of a given drug/combination and to improve patient survival.

Up to now, phase II trials have been developed in refractory/ relapsed osteosarcoma, with an inconsistent go or no-go decision to bring the drug in a first-line phase III trial, as no historical data were reliable. The increased number of new targeted and immune therapies have led to an increased number of trials testing these drugs, while the place of standard chemotherapy in relapse treatment is not properly defined. Most of the time, the choice of drugs to be introduced in refractory/relapsed osteosarcoma phase II trials had no specific osteosarcoma rationale $^{6}$, and when present, the rationale is based on primary tumor biology rather than metastatic biology. The increased availability in PDX models issued from relapsed metastatic disease might help to inform molecular-driven therapies, find biomarkers of efficacy, and possibly understand mechanisms underlying lack of efficacy but these immunodeficient models might not be as useful for immunotherapies. The number of models to be tested is a matter of debate. In addition, different relapse presentation might not benefit a therapy in the same way (for example, bulk disease versus minimal residual disease and lung versus bone metastasis).

Ideally, randomized phase II trials against placebo or standard treatment would help determine drug efficacy ${ }^{49,50}$, as the heterogeneity of the population can be taken into account by stratification. However, these randomized trials require more patients and thus are longer than single-arm trials. Bayesian trial designs might be of value in rapidly evaluating multiple treatments for rare tumors as done in Ewing sarcoma (rEECur trial ${ }^{65}$ and to integrate previous historical data (sarcoma 13 trial) ${ }^{45,66}$, tying to minimize the number of patients required.

An analysis of negative phase II trials was suggested to be used as historical control to rapidly evaluate future clinical trials in refractory/relapse osteosarcomas ${ }^{67}$. Using this approach, trials could be conducted in less than 3 years ${ }^{68}$. However, this analysis was based on refractory/relapsed osteosarcomas with either measurable disease according to RECIST (soft tissue component lesion greater than $1 \mathrm{~cm}$ ) or disease in complete remission after surgery. Patients with only evaluable disease were left out of this approach.

The use of biomarkers to classify individuals into smaller, biologically related groups would dramatically affect our approach to conducting clinical trials but might help to get better 
signal of efficacy. A basket trial based on molecular tumor characteristics across cancer types might be a useful approach to get efficacy signal.

In addition, the extrapolation of efficacy response in patients with refractory/relapsed osteosarcoma to patients with newly diagnosed disease is not established. Depending on the mechanism of the drug, the appropriate population to test a given drug might not be a population with relapsed disease. Thus, discussions on how to design trials and in which population the drug should be tested are critical for drug development in osteosarcoma, as well as preclinical evidence to bring a drug in the clinic, with more than one way of doing it.

\section{Closing summary}

To conclude, increasing osteosarcoma survival in the future will require broad expertise from key stakeholders from biology/bio-informatics to clinic and statistics and a joint effort to collect/connect all the available information on biology and clinical efficacy and build up new innovative strategies to test new drug efficacy in patients.
1. Trama A, Botta L, Foschi R, et al.: Survival of European adolescents and young adults diagnosed with cancer in 2000-07: population-based data from EUROCARE-5. Lancet Oncol. 2016; 17(7): 896-906.

PubMed Abstract | Publisher Full Text

2. Bielack SS, Smeland S, Whelan JS, et al.: Methotrexate, Doxorubicin, and Cisplatin (MAP) Plus Maintenance Pegylated Interferon Alfa-2b Versus MAP Alone in Patients With Resectable High-Grade Osteosarcoma and Good Histologic Response to Preoperative MAP: First Results of the EURAMOS-1 Good Response Randomized Controlled Trial. J Clin Oncol. 2015; 33(20): 2279-87.

PubMed Abstract | Publisher Full Text | Free Full Text

3. Marina NM, Smeland S, Bielack SS, et al:: Comparison of MAPIE versus MAP in patients with a poor response to preoperative chemotherapy for newly diagnosed high-grade osteosarcoma (EURAMOS-1): an open-label, international, randomised controlled trial. Lancet Oncol. 2016; 17(10): 1396-408. PubMed Abstract | Publisher Full Text | Free Full Text

4. Gaspar N, Occean BV, Pacquement $\mathrm{H}$, et al:: Results of methotrexate-etoposideifosfamide based regimen (M-EI) in osteosarcoma patients included in the French OS2006/sarcome-09 study. Eur J Cancer. 2018; 88: 57-66. PubMed Abstract | Publisher Full Text

5. Piperno-Neumann S, Ray-Coquard I, Occean BV, et al:: Results of API-AI based regimen in osteosarcoma adult patients included in the French OS2006/ Sarcome-09 study. Int J Cancer. 2020; 146(2): 413-23.

PubMed Abstract | Publisher Full Text | Faculty Opinions Recommendation

6. Omer N, Le Deley MC, Brugieres L, et al.: PHASE IITRIAL DESIGNS IN OSTEOSARCOMA RELAPSES: REVIEW OF PAST EXPERIENCE. Pediatr Blood Cancer. 2015; 62: Abstract O-078.

7. Gelderblom H, Jinks RC, Sydes M, et al:: Survival after recurrent osteosarcoma: data from 3 European Osteosarcoma Intergroup (EOI) randomized controlled trials. Eur J Cancer. 2011; 47(6): 895-902.

PubMed Abstract | Publisher Full Text

8. Kempf-Bielack B, Bielack SS, Jürgens $\mathrm{H}$, et al:: Osteosarcoma relapse after combined modality therapy: an analysis of unselected patients in the Cooperative Osteosarcoma Study Group (COSS). J Clin Oncol. 2005; 23(3): 559-68.

PubMed Abstract | Publisher Full Text

9. Anninga JK, Gelderblom H, Fiocco M, et al.: Chemotherapeutic adjuvant treatment for osteosarcoma: where do we stand? Eur J Cancer. 2011; 47(16): 2431-45.

PubMed Abstract | Publisher Full Text

10. Casali PG, Bielack S, Abecassis N, et al:: Bone sarcomas: ESMO-PaedCanEURACAN Clinical Practice Guidelines for diagnosis, treatment and follow-up. Ann Oncol. 2018; 29(Suppl 4): iv79-iv95. PubMed Abstract | Publisher Full Text

11. Marec-Berard P, Dalban C, Gaspar N, et al: A multicentric randomized phase II clinical trial evaluating high-dose thiotepa as adjuvant treatment to standard chemotherapy in patients with resectable relapsed osteosarcoma. Eur $J$ Cancer. 2020; 125: 58-68

PubMed Abstract | Publisher Full Text

12. Morrow JJ, Khanna C: Osteosarcoma Genetics and Epigenetics: Emerging
Biology and Candidate Therapies. Crit Rev Oncog. 2015; 20(3-4): 173-97. PubMed Abstract | Publisher Full Text | Free Full Text

13. Lorenz S, Barøy T, Sun J, et al.: Unscrambling the genomic chaos of osteosarcoma reveals extensive transcript fusion, recurrent rearrangements and frequent novel TP53 aberrations. Oncotarget. 2016; 7(5): 5273-88. PubMed Abstract | Publisher Full Text | Free Full Text

14. Behjati S, Tarpey PS, Haase K, et al.: Recurrent mutation of IGF signalling genes and distinct patterns of genomic rearrangement in osteosarcoma. Nat Commun. 2017; 8: 15936 .

PubMed Abstract | Publisher Full Text | Free Full Text

15. Perry JA, Kiezun A, Tonzi P, et al:: Complementary genomic approaches highlight the $\mathrm{PI} 3 \mathrm{~K} / \mathrm{mTOR}$ pathway as a common vulnerability in osteosarcoma. Proc Natl Acad Sci U S A. 2014; 111(51): E5564-73. PubMed Abstract | Publisher Full Text | Free Full Text | Faculty Opinions Recommendation

16. Zhao J, Dean DC, Hornicek FJ, et al:: Emerging next-generation sequencingbased discoveries for targeted osteosarcoma therapy. Cancer Lett. 2020; 474: $158-67$.

PubMed Abstract | Publisher Full Text | Faculty Opinions Recommendation

17. Ribi S, Baumhoer D, Lee K, et al.: TP53 intron 1 hotspot rearrangements are specific to sporadic osteosarcoma and can cause Li-Fraumeni syndrome. Oncotarget. 2015; 6(10): 7727-40. PubMed Abstract | Publisher Full Text | Free Full Text

18. Hameed M, Mandelker D: Tumor Syndromes Predisposing to Osteosarcoma. Adv Anat Pathol. 2018; 25(4): 217-22. PubMed Abstract | Publisher Full Text | Free Full Text | Faculty Opinions Recommendation

19. Chen D, Zhao Z, Huang Z, et al:: Super enhancer inhibitors suppress MYC driven transcriptional amplification and tumor progression in osteosarcoma. Bone Res. 2018; 6: 11

PubMed Abstract | Publisher Full Text | Free Full Text | Faculty Opinions Recommendation

20. Marchais A, et al: : Transcrptomic landscape of 79 homogenously treated osteosarcomas at diagnosis reveals tumor clones and microenvironment interplay associated with osteosarcoma prognosis. CTOS meeting abstract 3244146. 2019.

21. Brouchet-Gomez A, et al:: THE TEMPORAL DEREGULATION OF THE BALANCE BETWEEN THE ACTION OF MACROPHAGES AND OSTEOCLASTS IS ESSENTIAL FOR THE EFFECTIVENESS OF TREATMENT IN OSTEOSARCOMAS. CTOS meeting Abstract 3256389. 2019.

22. Kovac M, Blattmann C, Ribi S, et al.: Exome sequencing of osteosarcoma reveals mutation signatures reminiscent of BRCA deficiency. Nat Commun. 2015: 6: 8940.

PubMed Abstract | Publisher Full Text | Free Full Text

23. Ho XD, Phung $P$, van $L e Q$, et al.: Whole transcriptome analysis identifies differentially regulated networks between osteosarcoma and normal bone samples. Exp Biol Med (Maywood). 2017; 242(18): 1802-11.

PubMed Abstract | Publisher Full Text | Free Full Text 
24. Harttrampf AC, Lacroix L, Deloger M, et al.: Molecular Screening for Cancer Treatment Optimization (MOSCATO-01) in Pediatric Patients: A SingleInstitutional Prospective Molecular Stratification Trial. Clin Cancer Res. 2017; 23(20): 6101-12.

PubMed Abstract | Publisher Full Text

25. Forrest SJ, Geoerger B, Janeway KA: Precision medicine in pediatric oncology. Curr Opin Pediatr. 2018; 30(1): 17-24. PubMed Abstract | Publisher Full Text | Free Full Text Faculty Opinions Recommendation

26. Wang D, Niu X, Wang Z, et al:: Multiregion Sequencing Reveals the Genetic Heterogeneity and Evolutionary History of Osteosarcoma and Matched Pulmonary Metastases. Cancer Res. 2019; 79(1): 7-20. PubMed Abstract | Publisher Full Text | Faculty Opinions Recommendation

27. Dean DC, Shen S, Hornicek FJ, et al:: From genomics to metabolomics: emerging metastatic biomarkers in osteosarcoma. Cancer Metastasis Rev. 2018; 37(4): 719-31.

PubMed Abstract | Publisher Full Text | Faculty Opinions Recommendation

28. Barris DM, Weiner SB, Dubin RA, et al.: Detection of circulating tumor DNA in patients with osteosarcoma. Oncotarget. 2018; 9(16): 12695-704. PubMed Abstract | Publisher Full Text | Free Full Text Faculty Opinions Recommendation

29. Gambera S, Abarrategi A, González-Camacho F, et al:: Clonal dynamics in osteosarcoma defined by RGB marking. Nat Commun. 2018; 9(1): 3994. PubMed Abstract | Publisher Full Text | Free Full Text | Faculty Opinions Recommendation

30. Zhou Y, Yang D, Yang QC, et al.: Single-cell RNA-seq reveals identity and heterogeneity of malignant osteoblast cells and TME in osteosarcoma. 2020. Publisher Full Text

31. Engert $F$, Kovac M, Baumhoer D, et al.: Osteosarcoma cells with genetic signatures of BRCAness are susceptible to the PARP inhibitor talazoparib alone or in combination with chemotherapeutics. Oncotarget. 2017; 8(30): alone or in PubMed Abstract | Publisher Full Text | Free Full Text Faculty Opinions Recommendation

32. Holme H, Gulati A, Brough R, et al:: Chemosensitivity profiling of osteosarcoma tumour cell lines identifies a model of BRCAness. Sci Rep. 2018; 8(1): 10614.

PubMed Abstract | Publisher Full Text | Free Full Text |

Faculty Opinions Recommendation

33. Stewart E, Federico SM, Chen X, et al:: Orthotopic patient-derived xenografts of paediatric solid tumours. Nature. 2017; 549(7670): 96-100. PubMed Abstract | Publisher Full Text | Free Full Text | Faculty Opinions Recommendation

34. Sayles LC, Breese MR, Koehne AL, et al:: Genome-Informed Targeted Therapy for Osteosarcoma. Cancer Discov. 2019; 9(1): 46-63. PubMed Abstract | Publisher Full Text | Free Full Text | Faculty Opinions Recommendation

35. Buddingh EP, Kuijjer ML, Duim RAJ, et al.: Tumor-infiltrating macrophages are associated with metastasis suppression in high-grade osteosarcoma: $A$ rationale for treatment with macrophage activating agents. Clin Cancer Res. 2011; 17(8): 2110-9.

PubMed Abstract | Publisher Full Text

36. Fritzsching B, Fellenberg J, Moskovszky L, et al:: CD8 $^{+} /$FOXP3 $^{+}$-ratio in osteosarcoma microenvironment separates survivors from non-survivors: A multicenter validated retrospective study. Oncoimmunology. 2015; 4(3): e990800.

PubMed Abstract | Publisher Full Text | Free Full Text

37. Dumars C, Ngyuen JM, Gaultier A, et al:: Dysregulation of macrophage polarization is associated with the metastatic process in osteosarcoma. Oncotarget. 2016; 7(48): 78343-54

PubMed Abstract | Publisher Full Text | Free Full Text

38. Han Q, Shi H, Liu F: CD163 + M2-type tumor-associated macrophage support the suppression of tumor-infiltrating T cells in osteosarcoma. Int Immunopharmacol. 2016; 34: 101-6. PubMed Abstract | Publisher Full Text

39. Sundara YT, Kostine M, Cleven AHG, et al.: Increased PD-L1 and T-cell infiltration in the presence of HLA class I expression in metastatic high-grade osteosarcoma: A rationale for T-cell-based immunotherapy. Cancer Immunol Immunother. 2017; 66(1): 119-28.

PubMed Abstract | Publisher Full Text | Free Full Text Faculty Opinions Recommendation

40. Gomez-Brouchet A, Illac C, Gilhodes J, et al:: CD163-positive tumor-associated macrophages and CD8-positive cytotoxic lymphocytes are powerful diagnostic markers for the therapeutic stratification of osteosarcoma patients: An immunohistochemical analysis of the biopsies fromthe French OS2006 phase 3 trial. Oncoimmunology. 2017; 6(9): e1331193. PubMed Abstract | Publisher Full Text | Free Full Text
41. Kleinerman ES, Jia SF, Griffin J, et al.: Phase II study of liposomal muramyl tripeptide in osteosarcoma: The cytokine cascade and monocyte activation following administration. J Clin Oncol. 1992; 10(8): 1310-6. PubMed Abstract | Publisher Full Text

42. Meyers PA, Schwartz CL, Krailo M, et al:: Osteosarcoma: A Randomized, Prospective Trial of the Addition of Ifosfamide and/or Muramyl Tripeptide to Cisplatin, Doxorubicin, and High-Dose Methotrexate. J Clin Oncol. 2005; 23(9): 2004-11.

PubMed Abstract | Publisher Full Text

43. Meyers PA, Schwartz CL, Krailo MD, et al.: Osteosarcoma: The addition of muramyl tripeptide to chemotherapy improves overall survival--a report from the Children's Oncology Group. J Clin Oncol. 2008; 26(4): 633-8. PubMed Abstract | Publisher Full Text | Faculty Opinions Recommendation

44. Chou AJ, Kleinerman ES, Krailo MD: Addition of muramyl tripeptide to chemotherapy for patients with newly diagnosed metastatic osteosarcoma: A report from the Children's Oncology Group. Cancer. 2009; 115(22): 5339-48. PubMed Abstract | Free Full Text

45. Brard C, Piperno-Neumann S, Delaye J, et al: Sarcome-13/OS2016 trial protocol: A multicentre, randomised, open-label, phase II trial of mifamurtide combined with postoperative chemotherapy for patients with newly diagnosed high-risk osteosarcoma. BMJ Open. 2019; 9(5): e025877. PubMed Abstract | Publisher Full Text | Free Full Text

46. Tawbi HA, Burgess M, Bolejack V, et al.: Pembrolizumab in advanced softtissue sarcoma and bone sarcoma (SARC028): A multicentre, two-cohort, single-arm, open-label, phase 2 trial. Lancet Oncol. 2017; 18(11): 1493-501. PubMed Abstract | Publisher Full Text | Faculty Opinions Recommendation

47. Shemesh CS, Chanu $\mathrm{P}$, Jamsen $\mathrm{K}$, et al.: Population pharmacokinetics, exposure-safety, and immunogenicity of atezolizumab in pediatric and young adult patients with cancer. $J$ Immunother Cancer. 2019; 7(1): 314 PubMed Abstract | Publisher Full Text | Free Full Text

48. Le Cesne A, Marec-Berard P, Blay JY, et al.: Programmed cell death 1 (PD-1) targeting in patients with advanced osteosarcomas: Results from the PEMBROSARC study. Eur J Cancer. 2019; 119: 151-7.

PubMed Abstract | Publisher Full Text

49. Duffaud F, Mir O, Boudou-Rouquette P, et al.: Efficacy and safety of regorafenib in adult patients with metastatic osteosarcoma: $A$ noncomparative, randomised, double-blind, placebo-controlled, phase 2 study. Lancet Oncol. 2019; 20(1): 120-33. PubMed Abstract | Publisher Full Text | Faculty Opinions Recommendation

50. Davis LE, Bolejack V, Ryan CW, et al:: Randomized Double-Blind Phase II Study of Regorafenib in Patients With Metastatic Osteosarcoma. J Clin Oncol. 2019; 37(16): 1424-31.

PubMed Abstract | Publisher Full Text | Faculty Opinions Recommendation

51. Grignani G, Palmerini E, Dileo P, et al:: A phase II trial of sorafenib in relapsed and unresectable high-grade osteosarcoma after failure of standard multimodal therapy: An Italian Sarcoma Group study. Ann Oncol. 2012; 23(2): 508-16.

PubMed Abstract | Publisher Full Text

52. Xie L, Xu J, Sun X, et al.: Apatinib for Advanced Osteosarcoma after Failure of Standard Multimodal Therapy: An Open Label Phase II Clinical Trial. Oncologist. 2019; 24(7): e542-e550.

PubMed Abstract | Publisher Full Text | Free Full Text |

Faculty Opinions Recommendation

53. Italiano A, Penel N, Toulmonde $\mathrm{M}$, et al:: Cabozantinib in patients with advanced osteosarcomas and Ewing sarcomas: A French Sarcoma Group (FSG)/ US National Cancer Institute phase II collaborative study. Ann Oncol. 2018; 29 : viii753.

Publisher Full Text

54. Gaspar N, Casanova M, Sirvent FJB, et al.: Single-agent expansion cohort of lenvatinib (LEN) and combination dose-finding cohort of LEN + etoposide (ETP) + ifosfamide (IFM) in patients (pts) aged 2 to $\leq 25$ years with relapsed/ refractory osteosarcoma (OS). JCO. 2018; 36(15): 11527. Publisher Full Text

55. Grignani G, Palmerini E, Ferraresi V, et al.: Sorafenib and everolimus for patients with unresectable high-grade osteosarcoma progressing after standard treatment: A non-randomised phase 2 clinical trial. Lancet Oncol. 2015; 16(1): 98-107.

PubMed Abstract | Publisher Full Text | Faculty Opinions Recommendation

56. The WHO Classification of Tumours of Soft Tissue and Bone (Sarcomas). Liddy Shriver Sarcoma Initiative. 2015.

Reference Source

57. Lamora A, Talbot J, Mullard M, et al.: TGF- $\beta$ Signaling in Bone Remodeling and Osteosarcoma Progression. J Clin Med. 2016; 5(11): 96. PubMed Abstract | Publisher Full Text | Free Full Text

58. Ory B, Heymann MF, Kamijo A, et al.: Zoledronic acid suppresses lung metastases and prolongs overall survival of osteosarcoma-bearing mice. Cancer. 2005; 104(11): 2522-9. PubMed Abstract | Publisher Full Text

59. Heymann D, Ory B, Blanchard F, et al.: Enhanced tumor regression and tissue 
repair when zoledronic acid is combined with ifosfamide in rat osteosarcoma. Bone. 2005; 37(1): 74-86.

PubMed Abstract | Publisher Full Text

60. Piperno-Neumann S, Le Deley MC, Rédini F, et al.: Zoledronate in combination with chemotherapy and surgery to treat osteosarcoma (OS2006): A randomised, multicentre, open-label, phase 3 trial. Lancet Oncol. 2016; 17(8): 1070-80.

PubMed Abstract | Publisher Full Text | Faculty Opinions Recommendation

61. Li S, Chen P, Pei Y, et al.: Addition of Zoledronate to Chemotherapy in Patients with Osteosarcoma Treated with Limb-Sparing Surgery: A Phase III Clinical Trial. Med Sci Monit. 2019; 25: 1429-38. PubMed Abstract | Publisher Full Text | Free Full Text | Faculty Opinions Recommendation

62. Janeway KA, et al:: AOST1321, A PHASE 2 TRIAL OF RANKL ANTIBODY, DENOSUMAB, IN 2 COHORTS OF PATIENTS WITH RECURRENT OR REFRACTORY OSTEOSARCOMA: A REPORT FROM THE CHILDREN'S ONCOLOGY GROUP. CTOS meeting Abstract 3254462. 2019.

63. Roberts RD, Lizardo MM, Reed DR, et al.: Provocative questions in osteosarcoma basic and translational biology: A report from the Children's Oncology Group. Cancer. 2019; 125(20): 3514-25. PubMed Abstract | Publisher Full Text | Free Full Text | Faculty Opinions Recommendation
64. Biteau K, Guiho R, Chatelais M, et al.: L-MTP-PE and zoledronic acid combination in osteosarcoma: Preclinical evidence of positive therapeutic combination for clinical transfer. Am J Cancer Res. 2016; 6(3): 677-89. PubMed Abstract | Free Full Text

65. McCabe MG, Moroz V, Khan M, et al:: Results of the first interim assessment of rEECur, an international randomized controlled trial of chemotherapy for the treatment of recurrent and primary refractory Ewing sarcoma. JCO. 2019; 37 11007.

Reference Source

66. Brard C, Hampson LV, Gaspar N: Incorporating individual historical controls and aggregate treatment effect estimates into a Bayesian survival trial: A simulation study. BMC Med Res Methodol. 2019; 19(1): 85 PubMed Abstract | Publisher Full Text | Free Full Text

67. Lagmay JP, Krailo MD, Dang H, et al:: Outcome of Patients With Recurrent Osteosarcoma Enrolled in Seven Phase II Trials Through Children's Cancer Group, Pediatric Oncology Group, and Children's Oncology Group: Learning From the Past to Move Forward. J Clin Oncol. 2016; 34(25): 3031-8. PubMed Abstract | Publisher Full Text | Free Full Text Isakoff MS, Goldsby R, Villaluna D, et al.: A phase II study of eribulin in recurrent or refractory osteosarcoma: A report from the Children's Oncology Group. Pediatr Blood Cancer. 2019; 66(2): e27524.

PubMed Abstract | Publisher Full Text | Free Full Text |

Faculty Opinions Recommendation 